\title{
Effect of Water on Polypropylene/Barium Titanate Nanocomposites
}

\author{
Mohammad Syarif Azman and Lau Kwan Yiew* \\ School of Electrical Engineering, Universiti Teknologi Malaysia, 81310 UTM Skudai, Johor, Malaysia. \\ "Corresponding author: kwanyiew@utm.my

\begin{abstract}
In high voltage systems, it is important to have good insulation systems in order to transfer power over a long distance. The use of polymer nanocomposites could make differences in insulation system. However, the presence of water in nanocomposites could negatively affect the performance of nanocomposites as it is found that nanocomposites can absorb more water than unfilled polymers. This study investigated the AC breakdown strength of polypropylene (PP) as polymers blends with $1 \mathrm{wt} \%, 2 \mathrm{wt} \%$ and $5 \mathrm{wt} \%$ of barium titanate (BaTiO3) nanofiller and analyzed the effect of water absorption on breakdown strength of polypropylene added with different amount of barium titanate nanofiller. All the samples of nanocomposites were then subjected to water absorption process for certain periods which are 0 days, 10 days, and 20 days to evaluate how much water can be absorbed by the samples and its effect on breakdown strength of nanocomposites. While AC breakdown test was conducted according to standard of American Society for Testing ance Material (ASTM) D149 to correlate the effect of water absorption with the breakdown strength of nanocomposites containing barium titanate..
\end{abstract}

Keywords: polypropylene; barium titanate; polymer nanocomposites; water absorption; AC breakdown.

C) 2020 Penerbit UTM Press. All rights reserved

Article History: received 12 July 2020; accepted 16 August 2020; published 29 August 2020.

\section{INTRODUCTION}

In order to form new insulation systems that can cope with different stresses, it is crucial to augment the properties of insulating materials used in cables [1]. It is very critical in order to establish high voltage equipment with safety and stable operations. One of the important property in High Voltage insulation is breakdown strength and any improvement thereof can lead to significant advantages such as decrease of size and reduction of cost. Polymers' characteristics such as high protection to resist dielectric charge, thermal conductivity, chemical cavities and tree growth, accord them an advantage as insulation materials [2]. In electrical applications, many type of polymers such as polypropylene, polyethylene, polystyrene, poly (vinyl chloride) and synthetic rubber can be used as insulation [2].

Recently, nanocomposites become amusing topics due the particular characteristics this materials can show. Nanocomposites can be defined as combination of polymers and nanofillers that contain at least one dimension less than $100 \mathrm{~nm}$ in size. Desired dielectric properties can be accomplished by combining polymers and nanofillers [2]. The accomplishment of nanocomposites in relation to partial discharge (PD) and AC breakdown test is exceptional but the present of nanofillers could lead to the formation of agglomeration of the fillers which may abolish the true effectiveness of the composites [3].

However, the presence of water will affect the performance of nanocomposites in a negative way as underground high voltage insulation are mostly expose to water[4]. The effect of water on the breakdown strength of polymer blend with different weight percentage of nanofillers was therefore investigated through this project. The polypropylene was used as polymer and barium titanate (BaTiO3) was used as a nanofillers. The water absorption process was carried out on the samples and the samples went AC breakdown test.

\section{LITERATURE REVIEW}

Poplypropylene (PP) is a polymer that possesses excellent electrical insulation properties and heat resistance and can be obtained at low price but it is rigid and strong. Other than that, PP also can undergo simple manufacturing process without cross-linking process [5]. The recyclable criteria of PP also help it to be one of the promising polymer that can replace conventional polymers. Through the power line relay protection restrictions [5], limitation of maximum temperature for the cable short circuit or under fault conditions is $160{ }^{\circ} \mathrm{C}$. PP can maintain its mechanical strength and the cable can be avoid from thermal deformation damage below this temperature. PP insulated cables should have higher current carrying capacity since its blend crystallization temperature is about $160{ }^{\circ} \mathrm{C}$ and long-term operating temperature can be set at $120^{\circ} \mathrm{C}$.

While barium titanate (BaTiO3) nanofiller has been studied under numerous scientific and industrial application such as in transducers, dielectric capacitors and tunable phase shifter. BaTiO3 is one of the nanofillers that contain high dielectric breakdown strength [6]. Other than that, this materials have high permittivity which mean it has high ability to store electrical energy in an electrical field. 
BaTiO3 also had been used to enhance dielectric permittivity of polymers as it is nanofillers with high dielectric permittivity [7]. Also, BaTiO3 widely being used due to its low dielectric loss and high dielectric constant.

In addition, a nanocomposite is a combination between polymers and nanofillers to attain the desired dielectric properties [8]. The use of polymer nanocomposites is preferred as it can enhance dielectric breakdown strength. Due to the characteristic of nanofillers that have very high surface area-to-volume, the interfacial area of nanocomposites are greater than microcomposites. Other than that, such a small amount of nanofillers can be used for polymer nanocomposites which is less than $10 \%$ wt. The density of the intrinsic polymetric remain the same even though there are small amount of nanofillers added.

When epoxy nanocomposites were exposed to the surrounding that contained water, it absorbed significantly more water than unfilled polymer. Apparently, this was due to the present of nanoparticle-matrix interface, which could be preferred location for the aggregation of water molecules [9]. The presence of water molecules in nanocomposites might affect the electrical performance of nanocomposites in negative ways. Generally, polypropylene does not absorb water and the electrical properties of polypropylene also not change when expose to the water due to the hydrophobic nature of polymer which prevent water absorption. The choice of nanofillers can also effect the water level uptake as the nanofillers with hydrophilic properties will let the nanocomposites to absorb water.

The effect of water absorption was investigated by calculating the percentage of mass that increase after nanocomposites was immersed in water. The calculation was done by following the equation (1),

$$
\% \text { Mass }=\left|\frac{M_{w}-M_{d}}{M_{d}}\right| \times 100 \%
$$

where, $\mathrm{Mw}$ is weight measured after nanocomposites immersed in water and $\mathrm{Md}$ is weight measured before nanocomposites immersed in water.

Weibull analysis was used to analyze the data that collected from AC breakdown test. This distribution is a suitable tool to determine the breakdown strength due to the simple and useful graphical plot of failure data and had the ability to provide accurate failure analysis. From equation (2), breakdown strength were calculated. There twoparameters consisted in this distribution are $\alpha$ as the scale parameter and $\beta$ as the shape parameter.

$$
P(E)=1-e\left(\frac{E}{\alpha}\right)^{\beta}
$$

where,

$(E)$ is the cumulative probability of failure at $E$

$E$ is the experimental breakdown strength

$\alpha$ is the scale parameter

$\beta$ is the shape parameter

\section{METHODOLOGY}

The flowchart in Figure 1 shows the overview of the process for the experiment.

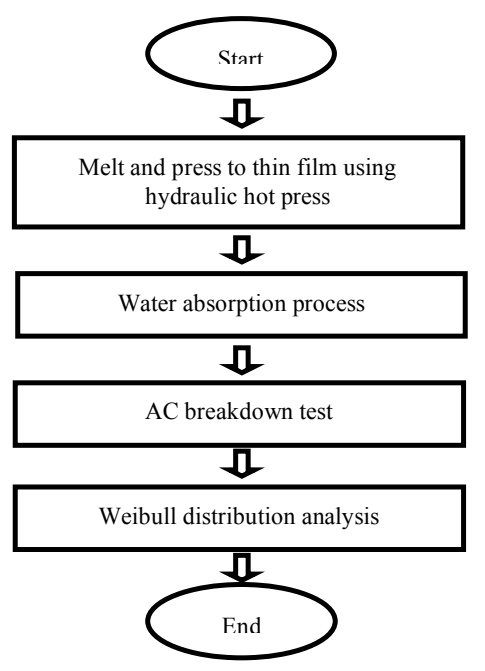

Figure 1. Flowchart of the overall experiment

The nanocomposite samples of $\mathrm{BaTiO} 3$ was pressed into thin film by using a hydraulic hot press machine as shown in Figure 2. Before pressing the samples into thin films, the samples were weighted approximately 0.5 gram by using Sartorius Analytical Balance Model BSA224S$\mathrm{CW}$ as shown in Figure 3. The temperature of the hydraulic hot press was set to $180{ }^{\circ} \mathrm{C}$ and the samples were placed between a pair of metal plate. The metal plate was used to mold the samples into circular shape thin film. Melinex paper was used to avoid any dust or unknown particles attached to the samples while the process took place. The melting and pressing process took place simultaneously at a pressing force of 2.5 ton for three min. Three samples were prepared for each type.

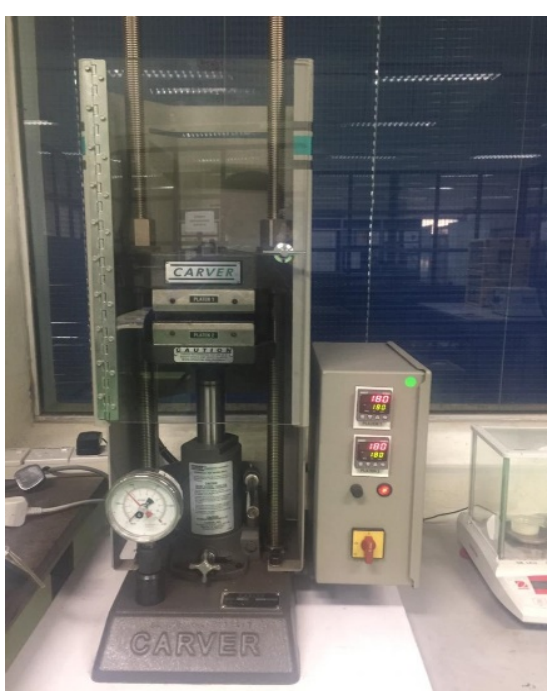

Figure 2. Hydraulic hot press machine 


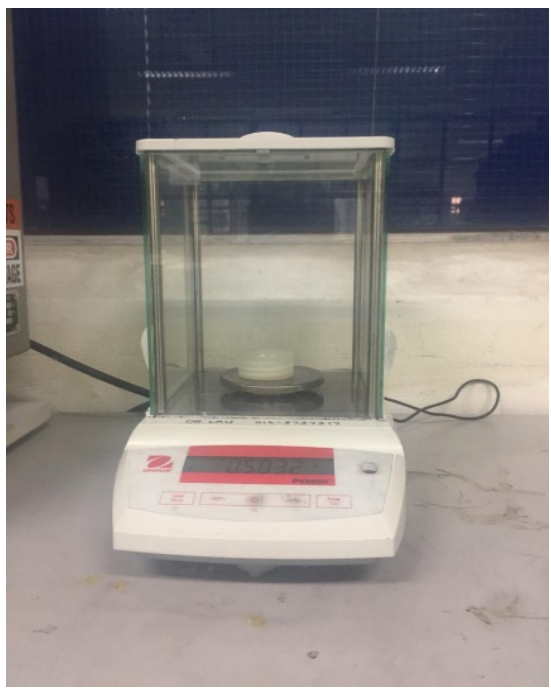

Figure 3. Sartorius Analytical Balance Model BSA224S-CW

After the samples were pressed into thin film, they underwent water absorption process. The weighed of the samples was taken before and after immersed in distilled water. Few period of times were used for water absorption process i.e. 0 days and 20 days. The samples that underwent 0 days of immersion in water would act as a reference. Filter paper was used to dried the samples after immersing in water, and the samples were weighed before undergoimg AC breakdown process.

By referring to the guideline provided in ASTM D149 standard, AC breakdown process will be carried out right after the samples were weighed after being immersed in water. Melinex paper was used for testing the condition of the transformer oil and the ball bearing either in good condition or otherwise before testing the samples. The sample was divided into several parts and was measured the thickness by using digital micrometer. 10 points was marked on the thin films of each sample for the $\mathrm{AC}$ breakdown test.

The thin film was placed between the two electrodes with ball bearing at the end of them and immersed in the transformer oil. This set up was shown in Figure 4. By using the transformer oil, surface flashover can be avoided as a precaution. The voltage was injected periodically by increasing it $1 \mathrm{kV}$ every 20 seconds until breakdown occurred. The equipment in Figure 5 was used to measure breakdown voltage which is HVAC/DC Test Set Meter. The test was repeated until reach to 10 points and all the data will be recorded for analysis. From equation (3), breakdown field strength can be calculated

$$
\text { Breakdown field strength }=\frac{\mathrm{kV}}{\mathrm{mm}}
$$

where,

$\mathrm{kV}$ is breakdown voltage

$\mathrm{mm}$ is thickness of the sample

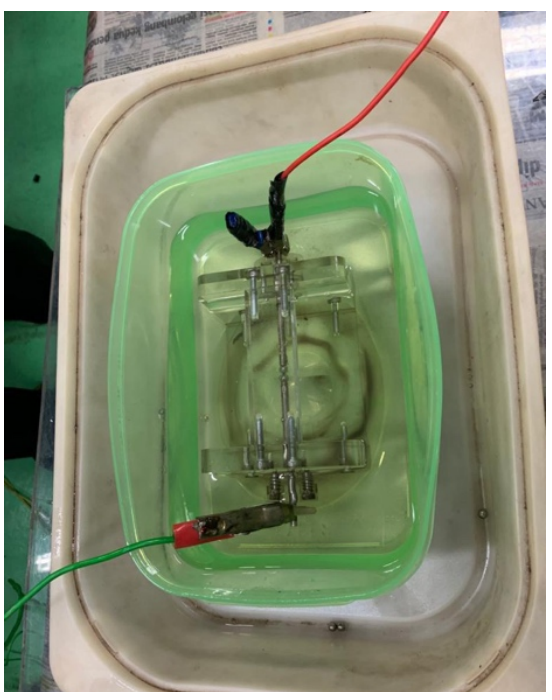

Figure 4. Electrode was immersed in transformer oil

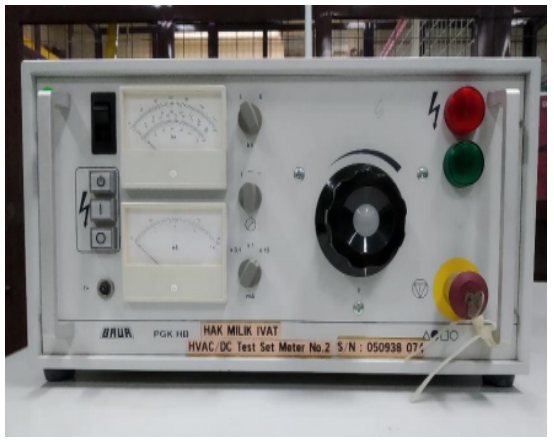

Figure 5. HVAC/DC Test Set Meter

Lastly, Weibull distribution analysis was used to analyze the data that had been recorded during $\mathrm{AC}$ breakdown test. There are two parameters There twoparameter that consisted in this distribution are $\alpha$ as the scale parameter which is the breakdown strength at $63.2 \%$ failure probability and $\beta$ as the shape parameter. This analysis consists reasonable accurate failure analysis and failure forecast with extremely small samples.

\section{RESULT AND ANALYSIS}

\subsection{Water Absorption Process}

Table 1. Percentage increase of mass for $1 \% \mathrm{wt}, 2 \% \mathrm{wt}$ and $5 \%$ wt of BaTiO3.

\begin{tabular}{|c|c|c|c|}
\hline Samples & $\begin{array}{c}\text { Initial weight } \\
(\mathrm{g}) \\
(0 \text { days })\end{array}$ & $\begin{array}{c}\text { Final weight } \\
(\mathrm{g}) \\
(20 \text { days })\end{array}$ & $\begin{array}{c}\text { Weight } \\
\text { difference } \\
\text { percentage } \mathrm{W} \\
(\%)\end{array}$ \\
\hline $1 \%$ wt BaTiO3 & 0.5066 & 0.5101 & 0.35 \\
\hline $2 \%$ wt BaTiO3 & 0.5127 & 0.5146 & 0.19 \\
\hline $5 \%$ wt BaTiO3 & 0.5072 & 0.5089 & 0.17 \\
\hline
\end{tabular}




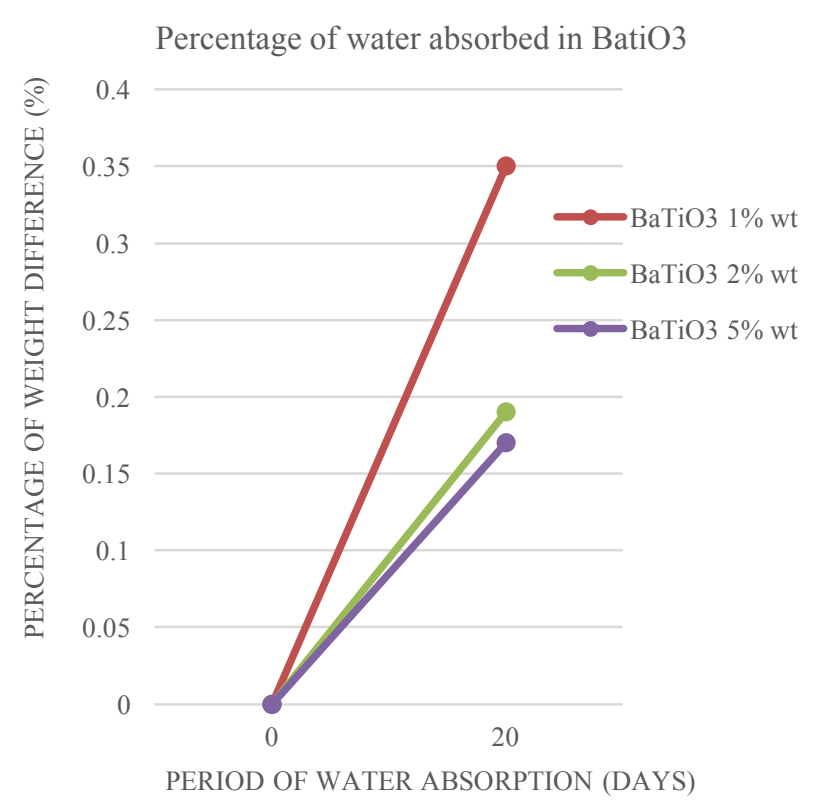

Figure 6. Percentage of water absorbed for $1 \% \mathrm{wt}, 2 \% \mathrm{wt}$ and $5 \%$ wt of BaTiO3.

Figure 6 and Table 1 shows water absorption characteristic for, nanocomposites with $1 \mathrm{wt} \%, 2 \mathrm{wt} \%$ and $5 \mathrm{wt} \%$ BaTiO3. Generally, after immersing in distilled water for 20 days the percentage of water uptake for $1 \mathrm{wt} \%$ of $\mathrm{BaTiO} 3$ is $0.35 \%$, percentage of water uptake for $2 \mathrm{wt} \%$ of $\mathrm{BaTiO} 3$ is $0.19 \%$ and percentage of water uptake for 5 $\mathrm{wt} \%$ of BaTiO3 is $0.17 \%$.

\subsection{AC Breakdown Strength Analysis}

For the breakdown strength of the nanocomposites, two methods were used to analyze the data which were use by average calculation and also Weibull distribution analysis. From Table 2, the average of dielectric strength for dry and wet condition were tabulated and from Figure 7 the chart represent the average of breakdown strength for both dry and wet conditions. While Table 3 was tabulated according to the Weibull distribution analysis and the Figure 8 represented Weibull plot distribution of samples for dry condition and Fig 9 represented Weibull plot distribution of samples for wet condition.

The results of breakdown strength for dry condition that had been obtained in Table 3 will be used as reference.

Table 2. Average of breakdown strength for dry and wet condition.

\begin{tabular}{|c|c|c|}
\hline \multirow[b]{2}{*}{ Samples } & \multicolumn{2}{|c|}{ Average Breakdown Strength $(\mathrm{kV} / \mathrm{mm})$} \\
\hline & $\begin{array}{l}\text { Dry condition } \\
\quad(0 \text { days })\end{array}$ & $\begin{array}{l}\text { Wet condition } \\
\text { ( } 20 \text { days })\end{array}$ \\
\hline $\begin{array}{c}\mathrm{PP}+1 \mathrm{wt} \% \\
\text { BaTiO3 }\end{array}$ & 68 & 46 \\
\hline $\begin{array}{c}\mathrm{PP}+2 \mathrm{wt}^{0} \% \\
\mathrm{BaTiO} 3\end{array}$ & 65 & 50 \\
\hline $\begin{array}{c}\mathrm{PP}+5 \mathrm{wt} \% \\
\text { BaTiO3 }\end{array}$ & 62 & 41 \\
\hline
\end{tabular}

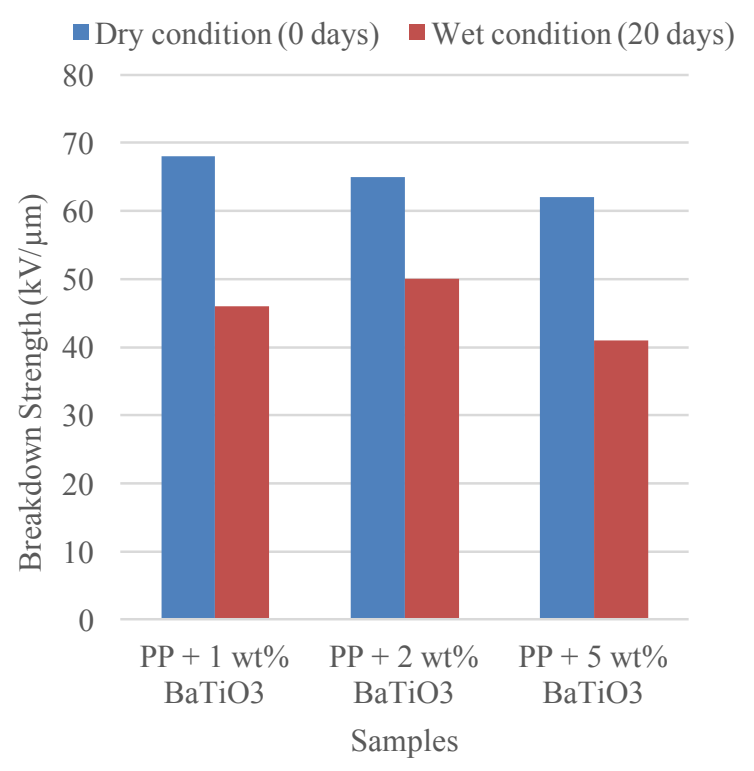

Figure 7. Average of breakdown strength for dry and wet condition.

Table 3 Weibull Distribution analysis for dry and wet condition

\begin{tabular}{|c|c|c|}
\hline \multirow{2}{*}{ Samples } & \multicolumn{2}{|c|}{ Average Breakdown Strength $(\mathrm{kV} / \mathrm{mm})(\beta)$} \\
\cline { 2 - 3 } & $\begin{array}{c}\text { Dry condition } \\
(0 \text { days })\end{array}$ & $\begin{array}{c}\text { Wet condition } \\
(20 \text { days })\end{array}$ \\
\hline $\begin{array}{c}\mathrm{PP}+1 \mathrm{wt} \% \\
\mathrm{BaTiO} 3\end{array}$ & $72 \pm 7(8)$ & $50 \pm 8(5)$ \\
\hline $\begin{array}{c}\mathrm{PP}+2 \mathrm{wt} \% \\
\mathrm{BaTiO} 3\end{array}$ & $70 \pm 7(7)$ & $54 \pm 6(7)$ \\
\hline $\begin{array}{c}\mathrm{PP}+5 \mathrm{wt} \% \\
\mathrm{BaTiO} 3\end{array}$ & $67 \pm 7(7)$ & $44 \pm 5(6)$ \\
\hline
\end{tabular}

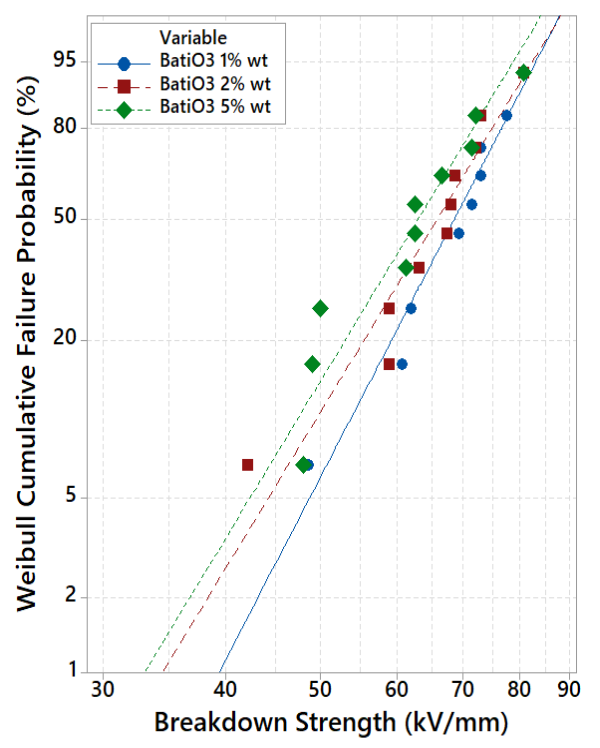

Figure 8. Weibull plot distribution of samples for dry condition 


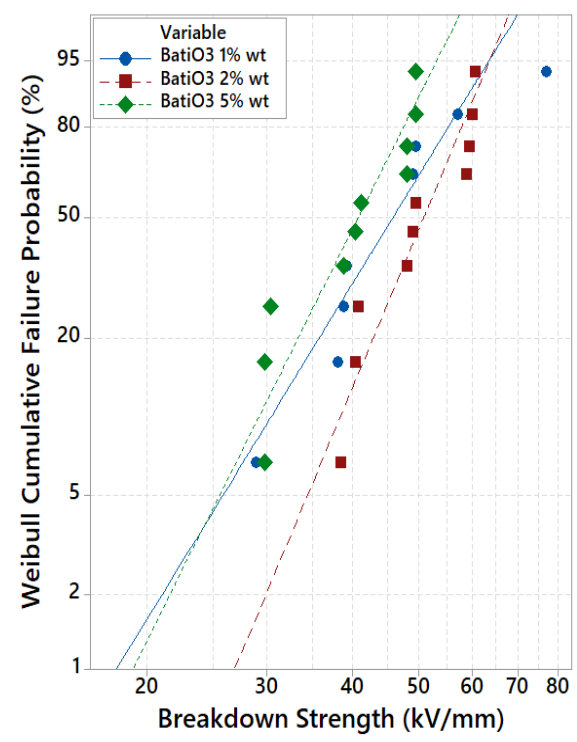

Figure 9. Weibull plot distribution of samples for wet condition

Figure 7 and Table 2 show average breakdown strength of $1 \mathrm{wt} \%, 2 \mathrm{wt} \%$ and $5 \mathrm{wt} \%$ BaTiO3 with and without water absorption process. The breakdown strength of $1 \mathrm{wt} \%$ of $\mathrm{BaTiO} 3$ for dry condition is $68 \mathrm{kV} / \mathrm{mm}$ which is the highest average breakdown strength followed by $2 \mathrm{wt} \%$ of BaTiO3 at $65 \mathrm{kV} / \mathrm{mm}$ and the lowest is $5 \mathrm{wt} \%$ of BaTiO3 at 62 $\mathrm{kV} / \mathrm{mm}$. While in Weibull analysis, it showed slightly different result for dry condition. Based on Table 3 and Figure 8 The breakdown strength of $1 \mathrm{wt} \%$ of $\mathrm{BaTiO} 3$ for dry condition is $72 \mathrm{kV} / \mathrm{mm}$ which is the highest average breakdown strength followed by $2 \mathrm{wt} \%$ of $\mathrm{BaTiO} 3$ at 70 $\mathrm{kV} / \mathrm{mm}$ and the lowest is $5 \mathrm{wt} \%$ of BaTiO3 at $67 \mathrm{kV} / \mathrm{mm}$.

After undergoing water absorption process for 20 days, based on Figure 7 and Table 2 they show the highest breakdown strength is $2 \mathrm{wt} \%$ of $\mathrm{BaTiO} 3$ at $50 \mathrm{kV} / \mathrm{mm}$ followed by $1 \mathrm{wt} \%$ of BaTiO3 at $46 \mathrm{kV} / \mathrm{mm}$ and the lowest is $5 \mathrm{wt} \%$ of BaTiO3 at $41 \mathrm{kV} / \mathrm{mm}$. From the Figure 9 and Table 3, the Weibull distribution of breakdown strength show the highest breakdown strength is $2 \mathrm{wt} \%$ of BaTiO3 at $54 \mathrm{kV} / \mathrm{mm}$ followed by $1 \mathrm{wt} \%$ of BaTiO3 at $50 \mathrm{kV} / \mathrm{mm}$ and the lowest is $5 \mathrm{wt} \%$ of BaTiO3 at $44 \mathrm{kV} / \mathrm{mm}$.

The results obtained from average breakdown strength and from Weibull distribution of breakdown strength for both condition can be compared. As the results from Weibull distribution of breakdown strength was obtained more accurately than average breakdown strength because Weibull distribution analysis could be able to provide accurate failure analysis and also Weibull distribution analysis is one of the suitable tool to determine the breakdown strength due to the simple and useful graphical plot of failure[10].

From Table 1, the nanocomposites show that after immersing in water for 20 days, the nanocomposites started to absorb more water. This is because the capabilities of polymers to absorb water is a result of hydroxyl group that existed on the surface of the composites[11]. Also presence of water in nanocomposites could affect the performance of breakdown strength of nanocomposites. This can be referred from Table 3 where the result of AC breakdown strength of $\mathrm{BaTiO} 3$ for wet condition, the breakdown strength decrease to $50 \mathrm{kV} / \mathrm{mm}$ from $72 \mathrm{kV} / \mathrm{mm}$ for $1 \mathrm{wt} \%$ of BaTiO3. For $2 \mathrm{wt} \%$ of BaTiO3 also followed the same pattern where the breakdown strength decrease from 70 $\mathrm{kV} / \mathrm{mm}$ to $54 \mathrm{kV} / \mathrm{mm}$. Lastly, the breakdown strength value of $5 \mathrm{wt} \%$ of BaTiO3 also decreasing from $67 \mathrm{kV} / \mathrm{mm}$ to 44 $\mathrm{kV} / \mathrm{mm}$. Detrimental effect could happen in insulation and dielectric materials due to the presence of water so it is crucial to keep the minum level of water in the materials[12]

When the amount of nanofillers was added to polymers was increased to $2 \mathrm{wt} \%$ and $5 \mathrm{wt} \%$ and before undergoing water absorption process the breakdown strength performance of the nanocomposites started to reduce. The reason behind the reducing performance could be due to the agglomeration factor of nanofillers. As the level of nanofillers increase, agglomeration could happen due overlapping of interfacial regions. Hence, less interphase volume is available within the nanocomposites polymers[12].

\section{CONCLUSION}

In conclusion, due to less agglomeration factor in the nanofillers, $1 \mathrm{wt} \%$ of $\mathrm{BaTiO} 3$ shows the highest breakdown strength for dry condition. After immersing in water for 20 days, $1 \mathrm{wt} \%, 2 \mathrm{wt} \%$ and $5 \mathrm{wt} \%$ of $\mathrm{BaTiO} 3$ shows decrement in the breakdown strength due to the presence water of water. The presence of water negatively affected the polymer nanocomposites due to the addition nanofillers. However, $2 \mathrm{wt} \%$ of $\mathrm{BaTiO} 3$ after undergoing water absorption process for 20 days shows an optimal dielectric properties because it had the highest breakdown strength in wet condition compared to others.

\section{ACKNOWLEDGMENT}

The authors thank Malaysia Ministry of Higher Education, Universiti Teknologi Malaysia and Nippon Sheet Glass Foundation for Materials Science and Engineering for financial sponsorship and the respective Fundamental Research Grant Scheme, FRGS (FRGS/1/2019/TK04/ UTM/02/1), RUG (16J55) and NSG (4B373) research grants.

\section{REFERENCES}

[1] N. M. K. Abdel-Gawad, A. Z. E. Dein, D. A. Mansour, H. M. Ahmed, M. M. F. Darwish and M. Lehtonen, "Enhancement of dielectric and mechanical properties of Polyvinyl Chloride nanocomposites using functionalized $\mathrm{TiO} 2$ nanoparticles," in IEEE Transactions on Dielectrics and Electrical Insulation, vol. 24, no. 6, pp. 34903499, Dec. 2017

[2] N. H. Rahim, K. Y. Lau, S. N. H. Kamarudin, N. A. Muhamad, N. Mohamad and W. A. W. A. Rahman, "Effect of Nanofiller Calcination on Breakdown Performance of Silica Based Polyethylene Nanocomposites," 2018 IEEE 7th International Conference on Power and Energy (PECon), Kuala Lumpur, Malaysia, 2018, pp. 91-95.

[3] N. A. Awang et al., "Partial Discharge and Breakdown Strength of Plasma Treated 
Nanosilica/LDPE Nanocomposites," 2018 5th International Conference on Electrical Engineering, Computer Science and Informatics (EECSI), Malang, Indonesia, 2018, pp. 391-394.

[4] C. Zou, J. C. Fothergill, and S. W. Rowe, "The effect of water absorption on the dielectric properties of epoxy nanocomposites," in IEEE Transactions on Dielectrics and Electrical Insulation, vol. 15, no. 1, pp. 106-117, February 2008. K. Elissa, "Title of paper if known," unpublished.

[5] C. J. Zheng, J. M. Yang, H. Zhao and Q. C. Chen, "AC performance, physical and mechanical properties of polypropylene/polyolefin elastomers blends," 2018 12th International Conference on the Properties and Applications of Dielectric Materials (ICPADM), Xi'an, 2018, pp. 910-913.

[6] Bele, A., Cazacu, M., Stiubianu, G., Vlad, S. and Ignat, M. (2015). Polydimethylsiloxane-barium titanate composites: Preparation and evaluation of the morphology, moisture, thermal, mechanical and dielectric behaviour. Composites Part B. Engineering, 68, pp.237-245.

[7] N. Gao, H. Xie, and Z. Peng, "Effect of Water Absorption on Dielectric Properties of EPDM/AI(OH), Composites," no. June, pp. 19-22, 2016.

[8] Rahim, N. H., Lau, K. Y., Kamarudin, S. N. H., Muhamad, N. A., Mohamad, N., \& Rahim, W. A. W. A. (2018). DC Breakdown Performance of Silica and Zirconia Based Polyethylene Nanocomposites. 2018 5th International Conference on Electric Power and Energy Conversion Systems,EPECS 2018, 278-282.

[9] K. Y. Lau, A. S. Vaughan, G. Chen and I. L. Hosier, "Dielectric response of polyethylene nanocomposites: The effect of surface treatment and water absorption," 2012 Annual Report Conference on Electrical Insulation and Dielectric Phenomena, Montreal, QC, 2012, pp. 275-278.

[10] A. Samad, K.Y. Lau, I.A. Khan, A.H. Khoja, d, M.M. Jaffar, M. Tahir, "Structure and breakdown property relationship of polyethylene nanocomposites containing laboratory-synthesized alumina, magnesia and magnesium aluminate nanofillers" Journal of Physics and Chemistry of Solids, 120, p 140-146,2018.

[11] N. H. Rahim, K. Y. Lau, N. A. Muhamad, N. Mohamad, and W. A. W. A. Rahman, "Effects of $\mathrm{SiO} 2$ and $\mathrm{ZrO} 2$ on the AC breakdown performance of polyethylene,"2017 IEEE Conf. Energy Conversion, CENCON 2017, vol. 2018-Janua, pp. 247-250, 2018.

[12] K. Y. Lau, A. S. Vaughan, and G. Chen, "Nanodielectrics: Opportunities and challenges,'IEEE Electr. Insul. Mag., vol. 31, no. 4, pp. 45-54, 2015.

[13] D. Fabiani and L. Simoni, "Discussion on application of the Weibull distribution to electrical breakdown of insulatingmaterials," IEEE Trans. Dielectr. Electr. Insul., vol. 12, no. 1, pp. 11-16, 2005. 